\title{
The Impact of Improved Lid of Underground Tanks "Tanka" On Breeding of An. Stephensi In Western Rajasthan, India
}

Himmat Singh ( $\sim$ hspawar@rediffmail.com )

National Institute of Malaria Research https://orcid.org/0000-0001-7682-651X

Sanjeev Kumar Gupta

ICMR-National Institute of Malaria Research: National Institute of Malaria Research

Kumar Vikram

ICMR: Indian Council of Medical Research

Rekha Saxena

ICMR-National Institute of Malaria Research: National Institute of Malaria Research

Amit Sharma

ICMR-National Institute of Malaria Research: National Institute of Malaria Research

Research

Keywords: Malaria, Tanka, Western Rajasthan, An. stephensi

Posted Date: April 6th, 2021

DOI: https://doi.org/10.21203/rs.3.rs-388440/v1

License: (c) (1) This work is licensed under a Creative Commons Attribution 4.0 International License. Read Full License 


\section{Abstract}

Background: Western Rajasthan of India has a typical desert climate. Until the introduction of canal water irrigation system, malaria was an unstable and seasonal occurrence. Due to scarcity of water, community practiced to have one large underground tank (locally known as Tanka) in their house to store water for long term use. Anopheles stephensi, one of the major malaria vectors, breeds in these "Tankas" if not properly covered and harbor a vector population throughout the year.

Methods: Two villages Ajasar (intervention) and Tota (control) with similar ecological features were selected for the study. A pre-assessment was carried out in both villages to assess lids of Tankas, their breeding profile and the adult mosquito density. Awareness of community about malaria and mosquitoes was also assessed during pre-assessment period. In intervention village, lids were replaced with improved polyvinyl lids that were mosquito proof and last longer than conventional lids. Fitness of the lids, was assessed after one year. Entomological assessment was carried out in both intervention and non-intervention villages. The level of awareness of community was assessed both during pre and post intervention.

Results : During the pre-assessment, Anopheles breeding was found in 22.1\% (58/262) of Tankas of intervention village and 27.1\% (19/70) of Tankas of control village. Tankas with iron lids were mainly positive in the intervention village (48.3\%) and the control village (42.1\%). In intervention village, 200 lids were replaced, and zero positivity was achieved.

Before intervention, the species composition of An. stephensi was $46 \%$ in intervention and $55 \%$ in control village. Per Man Hour Density (PMHD) of An. stephensi was significantly reduced to 0.55 (94.95\%) and 0.22 (97.8\%) in post-intervention and follow-up, respectively in intervention village.

Discussion: The adult density of An. stephensi was reduced significantly (97.8\%) in intervention village. Breeding in underground tankas was completely checked in intervention village as compared to the control, where no such substantial reduction was observed. The awareness level of the community was also improved due to their involvement in the study.

Conclusion: The study demonstrated that the small changes and interventions to reduce mosquitogenic conditions can be cost effective and long-lasting which may be helpful in control of malaria.

\section{Introduction}

Arid and semi-arid regions of western India are prone to malaria outbreaks ${ }^{1}$. In western India's desert region, major malaria epidemics have occured ${ }^{2}$, while malaria incidences in semi-arid and arid regions are affected by rainfall ${ }^{3}$. After the establishment of the Indira Gandhi Canal in Western Rajasthan in $1970^{4}$, the ecological scenario in terms of cropland and vegetated areas increased by $\sim 68 \%$ due to sufficient water supply ${ }^{5}$. The breeding of malaria vectors in Western Rajasthan is also aided by erratic rainfalls, migration and community water storage activities. The underground water tank (locally known as Tanka) is the primary water storage container in almost every house of Jodhpur, Jaisalmer, Barmer and Bikaner districts of Western Rajasthan. A Tanka is a rainwater collection system consists of covered, underground, impermeable cistern on shallow ground. Tankas collect rainwater from rooftops, courtyards, and artificially constructed catchments ${ }^{6}$.

According to studies, the lid of Tanka became cracked or damaged due to severe temperature variation in western Rajasthan, and became potential breeding sites for mosquitoes, especially An. stephensi, the malaria vector in western Rajasthan 7,8 . During summer season (April-June), Anopheles larvae are found in limited number of Tankas with missing or damaged lids, which act as mother foci and cater mosquitos during the monsoon and post monsoon season ${ }^{7}$. The aim of this study was to prevent breeding of mosquitoes in Tankas by improvising design of the lid from traditional iron to polyvinyl plastic. This improved design was supposed to minimize An. stephensibreeding and density in the study village.

\section{Materials And Methods}

Study Site: Jaisalmer, located in the Thar desert between $26^{\circ} .4^{\prime}$ and $28^{\circ} .23^{\prime}$ North Latitude and $69^{\circ} .20^{\prime}$ and $72^{\circ} .42^{\prime}$ East Longitude, is the largest district of Rajasthan and third largest in India. It shares international boundary in west with Pakistan and share district boundaries with Bikaner, Jodhpur and Barmer districts. Malaria has become a major problem in desert areas as a result of increased water availability for irrigation and drinking after introduction of Indira Gandhi Nahar Pariyojana9.

The district of Jaisalmer is divided into four blocks: Jaisalmer, Pokaran, Fatehgarh, and Bhaniyana. Pokaran has been the most affected by malaria compared to other blocks ${ }^{10}$. Ajasar village in Pokaran block, with population of around 1500 people, was chosen for the study due to higher API (>5) and after consulting with the Medical Officer of CHC Pokhran during August 2017. Tota, the non-intervention village about $7 \mathrm{~km}$ from the study village and with similar geographical, ecological and malarious conditions was also selected for the research (Fig.1).

Entomological surveillance: Malaria transmission in the Thar desert of India is primarily caused by An. stephensi ${ }^{11}$, which breeds almost exclusively in the underground water reservoirs such as 'tanka' and 'beri'".

To evaluate adult and larval mosquito breeding of An. stephensi, entomological surveillances were conducted during pre-intervention (May 2018), postintervention (June, 2018), and follow-up (May, 2019) Adult mosquitoes were collected using two methods: hand catch and total catch, as per standard WHO manual ${ }^{12}$. 
Hand catch: Mosquitoes resting inside human dwellings, cattle sheds and mixed dwellings were collected by insect collectors using flash light and mouth aspirators during the early morning hours (6 to 8 AM). Standard keys were used to identify mosquitoes. Per Man Hour Density (PMHD) of each Anopheles species was calculated (PMHD = Total no. of mosquitoes collected / No. of person $x$ Time spent in hours).

Total catch: Mosquitoes resting inside structure were sampled, also known as spray sheet collection. Indoor resting mosquitoes were collected on white cotton sheets using this approach after being knocked with pyrethrum extract. Cotton sheets were laid out on the floor of the room, and pyrethrum was sprayed to cover the area. After ten minutes, the mosquitoes killed by the spray were collected in petri dishes lined with wet cotton or filter paper from sheets spread on the floor and transported to the laboratory.

Larval collection: Breeding site surveys were conducted in all habitats around and within villages by standard WHO methods. Sampling was done with a dipper of white enamel bowl from Tanka, clay pot/bird pots, under construction Tanka, cement cattle tank, ground cement tanks and seepage water. Larvae were identified using standard identification keys after emergence at adult stage.

Intervention: A total of 200 Tanka's lids (18x18 inch) were replaced after receiving consent from house owners in Ajasar village. To prevent mosquito breeding in Tankas, improvisations in lid design were developed. The material of the lid was converted from traditional Iron or others materials to the polyvinyl plastic with rust resistant steel screws at the hinge joint of the lids (Fig. 2).

Information, Education and Communication (IEC) activities: During the pre-intervention phase, IEC activities included conducting a door-to-door survey, meeting with the Sarpanch, Block Development Officer (BDO) and community representatives to inform the community about the study's goal, benefits, and obtain consent. Skilled manpower (known as Mistry') were also selected from the Ajasar village and trained on the entire process of replacing lids in the presence of the Sarpanch and other important community representatives (Fig.3)

Knowledge, Attitude and Practices (KAP) study: A KAP study was also conducted to assess community knowledge about malaria, mosquitoes, their breeding places, and the role of Tankas in malaria transmission before and after the intervention. A total of 120 household persons participated in the KAP study, both pre and post replacement of the lids.

Fitness of Tankas: Tankas with damaged or missing lids were labelled and geo-referenced using GPS for future replacement in Ajasar village only during preintervention phase. The fitness of the lids, as well as their ability to prevent mosquito breeding was examined during the follow-up after one year.

\section{Results}

Impact of lid replacement on positivity of Tankas: In pre-intervention phase of the study, $22.1 \%(58 / 262)$ Tankas in the intervention village (Ajasar) and 27.1\% $(19 / 70)$ of Tankas in non-intervention village (Tota) found positive. Positivity was not statistically significant between intervention and non-intervention village $(z=-0.8814, p=0.37886>0.05$, not significant) indicates that there was no difference in positivity until the lids were replaced.

Tankas with iron lid were found in the maximum numbers in intervention and non-intervention villages, with $48.3 \%(28 / 58)$ and $42.1 \%(8 / 19)$ respectively. In the intervention and non-intervention villages, positivity of Tankas with iron lids was $19.6 \%$ and $21.6 \%$, respectively. Tankas under construction ( $60 \%$ intervention, $100 \%$ - non-intervention), Tankas with wooden lids (75\% in intervention) and Tankas without lids (33.3\%-intervention, $61.5 \%$-non-intervention) were found to be prone to mosquito breeding (Table 1).

Table 1: Positivity in different types of lids of Tanka pre- and post- intervention in both villages

\begin{tabular}{|c|c|c|c|c|c|c|c|c|c|c|c|c|}
\hline \multirow[t]{3}{*}{ S.N } & \multirow[t]{3}{*}{ Type of Lid } & \multicolumn{4}{|c|}{ Pre-Assessment } & \multirow{2}{*}{\multicolumn{2}{|c|}{$\begin{array}{l}\text { Intervention Phase* } \\
\text { Intervention }\end{array}$}} & \multicolumn{4}{|c|}{ Post -Intervention } & \multirow{3}{*}{$\begin{array}{l}\text { Folls } \\
\text { Inter } \\
\begin{array}{l}\text { Nurr } \\
\text { chec }\end{array}\end{array}$} \\
\hline & & \multicolumn{2}{|c|}{ Intervention } & \multicolumn{2}{|c|}{ Non-Intervention } & & & \multicolumn{2}{|c|}{ Intervention } & \multicolumn{2}{|c|}{ Non-Intervention } & \\
\hline & & $\begin{array}{l}\text { Number } \\
\text { checked }\end{array}$ & $\begin{array}{l}\text { Positive } \\
\text { (\% } \\
\text { positivity) }\end{array}$ & $\begin{array}{l}\text { Number } \\
\text { checked }\end{array}$ & $\begin{array}{l}\text { Positive } \\
\text { (\% } \\
\text { positivity) }\end{array}$ & $\begin{array}{l}\text { Lid } \\
\text { Replaced }\end{array}$ & $\begin{array}{l}\text { Replacement } \\
\text { (\%) }\end{array}$ & $\begin{array}{l}\text { Number } \\
\text { checked }\end{array}$ & $\begin{array}{l}\text { Positive } \\
\text { (\% } \\
\text { positivity) }\end{array}$ & $\begin{array}{l}\text { Number } \\
\text { checked }\end{array}$ & $\begin{array}{l}\text { Positive } \\
(\% \\
\text { positivity) }\end{array}$ & \\
\hline 1 & Iron & 143 & $28(19.6)$ & 37 & $8(21.6)$ & 129 & 90.2 & 200 & $0(\%)$ & 31 & $2(6.5)$ & 200 \\
\hline 2 & Aluminum & 7 & $2(28.6)$ & 0 & $0(0.0)$ & 5 & 71.4 & & & 0 & 0 & \\
\hline 3 & Wooden & 4 & $3(75.0)$ & 0 & $0(0.0)$ & 4 & 100.0 & & & 0 & 0 & \\
\hline 4 & Polyvinyl & 55 & $6(10.9)$ & 19 & $2(10.5)$ & 14 & 25.5 & & & 16 & $1(6.3)$ & \\
\hline 5 & Without Lid & 48 & $16(33.3)$ & 13 & $8(61.5)$ & 48 & 100.0 & & & 10 & $2(20)$ & \\
\hline \multirow[t]{2}{*}{6} & $\begin{array}{l}\text { Under } \\
\text { construction }\end{array}$ & 5 & $3(60.0)$ & 1 & $1(100.0)$ & 0 & 0.0 & & & 5 & $1(20)$ & \\
\hline & Total & 262 & $58(22.1)$ & 70 & $19(27.1)$ & 200 & 76.3 & 200 & $0(0 \%)$ & 62 & $6(9.7)$ & 200 \\
\hline \multicolumn{13}{|c|}{ * No replacement of lids in non-intervention village } \\
\hline & nwas do & $f \circ f^{\prime}$ & mi & ced lidci & 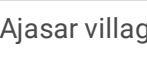 & & & & & & & \\
\hline
\end{tabular}

Impact of lid replacement on adult collection of An. stephensi: During pre-assessment period, An. stephensi comprised of $46 \%$ (99/216) and 55\% (54/98) in intervention and non-intervention sites respectively collected using hand-catch adult collection method, while during post-intervention and follow-up conducted 
during 2018 and 2019 respectively, composition of $A n$. stephensi reduced significantly to $17 \%(5 / 29)$ [z=2.925, p =0.00338, significant at $p<.05]$ and 7\% $(2 / 27)[z=3.8197, p=0.00014$, significant at $p<.05]$ respectively in intervention village. In non-intervention village, An. stephensi remained predominant to $32 \%(21 / 66)$ and $33 \%$ (27/82) during post-intervention and follow-up, respectively (Fig.4).

In total-catch adult collection method, before replacement of lids, An. stephensi comprises of 66\% (80/122) and 76\% (62/82) in intervention and nonintervention village respectively. While in post-intervention and follow-up, An. stephensi composition reduced significantly to $9 \%(1 / 11)[z=3.6768, p=0$ .00024 , significant at $\mathrm{p}<.05]$ and $11 \%(2 / 19)[z=4.5245, \mathrm{p}<0.00001$, significant at $\mathrm{p}<.05]$ respectively in intervention village. An. stephensi remained predominant in non-intervention village 52\% (11/21) and 52\% (32/62) in follow-ups 2018 and 2019 respectively (Fig. 5).

Impact of lid replacement on larval Collection: In addition to Tankas, mosquitoes were also collected from seepage water, pipeline leakage, bird pots, plastic tanks, coolers and cement tanks. In pre-assessment, An. stephensi was predominant in both intervention and non-intervention villages in Tankas while during both post-assessment and follow-up,An. stephensi emerged from Tankas in non-intervention village only .

Impact of lid replacement on Per Man Hour Density (PMHD) of Anopheles mosquitoes: An. stephensi had the highest PMHD (10.9 and 11.8 in intervention and non-intervention villages, respectively) in pre-assessment, followed by An. culicifacies (Fig.6). PMHD of An. stephensi in intervention village reduced significantly to $0.55(94.95 \%)$ in post-intervention and to 0.22 (97.8\%) in follow-up. The reduction of An. stephensi in non-intervention village was moderate, at $4.6(61.1 \%)$ and $5.9(50 \%)$ in post-intervention and follow-up phase, respectively.

Results of KAP study undertaken in intervention village: A KAP research was performed during a door-to-door survey conducted before and after the lids replacement, with questions about malaria breeding sites, mosquito larvae detection, and other topics. A total of 120 people from different households took part in the survey. There was a substantial increase in respondents' awareness levels. (Fig 7).

Pre-assessment result showed that $67 \%$ respondents were aware about the malaria disease and $37 \%$ knew that malaria spreads through the bite of female mosquitoes. Only $11 \%$ respondents were aware that larva is a part mosquito's life cycle whereas $20 \%$ of the respondents knew that mosquitoes breed in Tankas. During intervention, IEC was imparted to the villagers through house-to-house approach and by community gathering in the presence of the Sarpanch and BDO. In follow-up conducted after one year, there was a significant improvement in the knowledge of respondents $(n=120)$. The awareness about malaria increased from $67-89 \%\left(X^{2}=17.65\right.$, significant at $\left.p<0.001\right)$; knowledge about malaria spread through the bite of female mosquitoes improved from $37-68 \%$ $\left(X^{2}=24.13\right.$, significant at $\left.p<0.001\right)$; knowledge about larval form as a part of mosquito life cycle improved from $11-78 \%\left(X^{2}=110.65\right.$, significant at $\left.p<0.001\right)$; and the awareness about breeding of mosquitoes in Tankas from $20-74 \%\left(X^{2}=70.66\right.$, significant at $\left.p<0.001\right)$.

\section{Discussion}

Rajasthan is in category 1 of the National Framework of Malaria Elimination in India 2016-203013 because the overall API of the state $<1$. Western Rajasthan, which was an unstable malaria zone prior to the establishment of the Indira Gandhi Canal in 1970, has become a regular feature in its command areas, indicating a changed malariological scenario ${ }^{14}$.

Since the community living in this zone were devoid of potable water, they used Tanka (underground tank) for year-round storage in nearly every house. As it is known, that An. stephensi adapted for breeding in Tankas (Underground tanks) and beris (Wells) throughout the year ${ }^{7}$. With the increase in water supply of Indira Gandhi Canal, the resident population increased in few decades and so more Tankas came into existence, fueling bigger mosquito breeding habitats and malaria transmission. Availability of water and improper lids allowed mosquito breeding in these Tankas.

Almost all houses in western Rajasthan use Tankas for their daily water needs and long term storage. Tanka is an important feature which improves selfreliance of the rural people, stabilizes rural employment skills, and cost-effective ${ }^{6}$. An. stephensi which is the major malaria vector of western Rajasthan predominantly breeds in these Tankas ${ }^{7}$. Our pre-awareness study (KAP) of the community showed that about $67 \%$ individuals were aware of malaria as disease spread by mosquitoes and about $44 \%$ knew it spreads due to infective bites of female Anopheles. This shows a fair awareness of the community about the diseases and its transmitting agent. However, community did not know much about larvae (13\%) and $20 \%$ knew that breeding occurs in Tankas (Fig. 7). Similar results were observed in study conducted by Yadav et.al ${ }^{15}$, which also showed that about $20 \%$ of respondent have knowledge that Tanka is main source of mosquito breeding and its proper coverage is essential in prevention of mosquito breeding ${ }^{16}$. Our results showed that there was significant improvement in the knowledge of community (22-67\%) about malaria, its transmission and breeding sites. The significant improvement may be due to active engagement of villagers in lid replacement process during the study. The knowledge gained by community will be helpful in understanding the importance proper lids and mosquito proofing of Tankas.

Damage lids provide opportunity to An. stephensi to breed in these Tankas. During hot summer season, when outdoor temperature exceeds $>45^{\circ} \mathrm{C}$, these Tankas becomes resting place for the mosquitoes to avoid desiccation. During monsoon and post-monsoon season, An. stephensibreeds profusely and support malaria along with another vector species i.e. An. culicifacies. An culicifacies, is a seasonal malaria vector of the Western Rajasthan, which appears in post-monsoon and winter season only. Study by Joshi et al (2005) showed that An. stephensi is a persistent malaria causing vector of the region, which is supported by An. culicifacies in the post-monsoon season ${ }^{17}$

Installation of improved polyvinyl lids has completely stopped breeding in these Tankas. As a result of which there was drastic reduction in density of An. stephensi (94.9\% in post-intervention \& $97.9 \%$ in follow-up after one year) in Ajasar the intervention village as compared to non-intervention Tota village. After one year of Installation of improved lids the fitness was checked during May, 2019. A total of 98\% (196/200) replaced lids were found fit and were free from 
breeding. Furthermore, they had no rusting at hinge joints except for 4 lids, where 2 lids were found detached from cement binding, probably due to use of lids prior to cement settling, and 2 had breeding, possibly due to holding lids open for long periods of time.

According to the World Malaria Report $2019^{18}$, almost $85 \%$ of the global malaria burden is distributed in nineteen countries of Sub-Saharan Africa and India. India accounted for $47 \%$ of the P. vivax burden. Seven states of India viz. Jharkhand, West Bengal, Uttar Pradesh, Chhattisgarh, Odisha, Gujarat and Madhya Pradesh contributed a combined $90 \%$ of cases. In Rajasthan $P$. falciparum is very low in about only $8 \%$ of malaria cases in 2016 which has increased to about $13 \%$ in 2020. Malaria cases have declined from 12741 in 2016 to 674 in 2020 (up to September) ${ }^{19}$. However, reduction in parasite incidences also relate to good intervention. In case of Rajasthan there might be impact of reduced malaria in Odisha and other zones where inhabitants of western Rajasthan usually go for livelihood and labour migrate from these places to western Rajasthan for work also. Availability of vectors like An. stephensi during the immigration of such person coming to village either post-monsoon for crop purpose of visit of laborers for developmental activities might introduce parasite in the village system for transmission ${ }^{17}$.

\section{Conclusion}

The current study has successfully shown that small interventions can efficiently solve an emerging problem. A significant reduction in density of $A n$. stephensi was observed using mosquito proof lids, addressing the problem of persistent mosquito (An. stephensi) breeding in underground tanks. The modified polyvinyl plastic lids are cost-effective and have a life expectancy of 2 to 5 years if used properly. Lids not only keep mosquito away, but they also keep other opportunistic insects and reptiles like lizards, snakes, and rodents out of portable water.

Rajasthan is a low malaria transmission area, falling under Category 1 of the WHO's malaria elimination target for 2030. These novel measures could help to curb perennial malaria transmission by reducing the responsible vector, which may be responsible for year-round malaria transmission. Such simple long-term interventions are critical because they reduce routine intervention costs, reduce insecticide waste, and protect the environment.

\section{Abbreviations}

PMHD - Per Man Hour Density

KAP - Knowledge, Attitude and Practices

WHO - World Health Organization

\section{Declarations}

\section{Acknowledgement}

Authors are thankful to Indian Council of Medical Research for providing financial support to conduct the study. Thanks are also due to state health department of Jaisalmer, Rajasthan for providing valuable inputs essential for the study. Authors are thankful to the Sarpanch of Ajasar village for supporting the intervention and motivating the villagers. Last but not least, thanks are due to Mr. Hariom Tyagi, Mr. Hira Kant Jha and other team members for providing technical support to the study.

\section{Authors Contributions}

HS conceived the study that was completed by SG, KV, RS. All authors wrote the paper that was drafted by HS and SG. The overall study was coordinated by the Director NIMR and funded by ICMR. All authors read and approved the final manuscript.

\section{Competing Interests}

The authors declare that there is no conflict of interest regarding the publication of this article.

\section{Disclaimers:}

The views expressed in the submitted article are our own and not an official position of the institution or funder.

\section{Sources of support: None}

Funding: Indian Council of Medical Research, New Delhi, India

Data sharing: No additional data.

Ethical Approval: Not required, however, consents were taken from villagers.

\section{References}

1. Lingala MAL. Effect of meteorological variables on Plasmodium vivax and Plasmodium falciparum malaria in outbreak prone districts of Rajasthan, India. J Infect Public Health. 2017;10(6):875-880. doi: 10.1016/j.jiph.2017.02.007, PMID 28285973. 
2. Tyagi BK, Chaudhary RC, Yadav SP. Epidemic malaria in Thar desert, India. The Lancet. 1995;346(8975):634-5. doi:10.1016/s0140-6736(旬) $91462-5$, PMID $\underline{7651016}$.

3. Mathur KK, Harpalani G, Kalra NL, Murthy GGK, Narasimham MVVL. Epidemic of malaria in Barmer district (Thar Desert) of Rajasthan during 1990. Indian J Malariol. 1992;29(1):1-10. PMID 1459294.

4. Kharol SK, Kaskaoutis DG, Badarinath KVS, Sharma AR, Singh RP. Influence of land use/land cover (LULC) changes on atmospheric dynamics over the arid region of Rajasthan state, India. J Arid Environ. 2013;88:90-101. doi:10.1016/j.jaridenv.2012.09.006.

5. Gardiner V. The Indira Gandhi Canal, Rajasthan, India. Geography. J Geogr assoc Sheffield Engl. 1987;72(3):251.

6. Vangani NS, Sharma KD, Chatterji PC. Tanka-A Reliable system of rainwater harvesting in the Indian desert. Jodhpur: Central Arid Zone Research Institute; 1988. p. 33.

7. Tyagi BK, Yadav SP. Malariological and sociological significance of 'tanka' and 'beri' in the Thar Desert, Western Rajasthan, India. J Arid Environ. 1996;33(4):497-501. doi:10.1006/jare.1996.0085.

8. Tyagi BK, Yadav SP, Sachdev R, Dam PK. Malaria outbreak in the Indira Gandhi Nahar Pariyojana Command Area in Jaisalmer district, Thar Desert, India. J Commun Disord. 2000;33:88-95.

9. Yadav SP. A study of treatment seeking behaviour for malaria and its management in febrile children in rural part of desert, Rajasthan, India. J Vector Borne Dis. 2010;47(4):235-42. PMID 21178217.

10. Chalga MS, Dixit AK, Shah B, Bhati AS. Real time health informatics system for early detection and monitoring of malaria in desert district, Jaisalmer, India. J Health Inform Dev Ctries. 2011:28: 6-298.

11. Mohanty SS, Meena S, Kanojia PC. A comparative study of energy contents in mosquito vectors of malaria and dengue prevailing in Jodhpur city (Thar Desert) of Rajasthan State, India. J Arthropod Borne Dis. 2018;12(3):286-95. PMID 30584552.

12. World Health Organization. Manual on Practical Entomology in Malaria: methods and techniques World Health Organization; 1975. P. 191.

13. National framework of malaria elimination in India 2016-2030. 2016. Available from:https://www.who.int/docs/default-source/searo/india/health-topicpdf/national-framework-malaria-elimination-india-2016-2030.pdf?sfvrsn=606b352a_2. Accessed 21 March 2021.

14. Tyagi BK, Yadav SP. Bionomics of malaria vectors in two physiographically different areas of the epidemic-prone Thar Desert, north-western Rajasthan (India). J Arid Environ. 2001;47(2):161-72. doi:10.1006/jare.2000.0698.

15. Yadav SP, Tyagi BK, Ramnath T. Knowledge, attitude and practice towards malaria in rural communities of the epidemic-prone Thar Desert, northwestern India. J Commun Dis. 1999 Jun;31(2):127-36. PMID 10810601.

16. Tyagi BK. Medical Entomology- A handbook of medically important insects and other arthropods. India: Scientific Publishers, Jodhpur; 2003 . pp. 1-34.

17. Joshi V, Sharma RC, Singhi M, Singh H, Sharma K, Sharma Y, Adha S. Entomological studies on malaria in irrigated and non-irrigated areas of Thar Desert, Rajasthan, India. J Vector Borne Dis. 2005;42(1):25-9. PMID 1 15999458.

18. World Health Organization. World malaria report 2019 [internet]. WHO. 2019; 232 pp. Available from: https://www.who.int/publications-detail/worldmalaria-report-2019. Accessed 21 March 2021.

19. National Vector Borne Disease Control Program. NVBDCP 2020. Available from: https://nvbdcp.gov.in/index1.php?lang=1\&level=1\&sublinkid=5784\&lid = 3689). Accessed 21 March 2021.

\section{Figures}

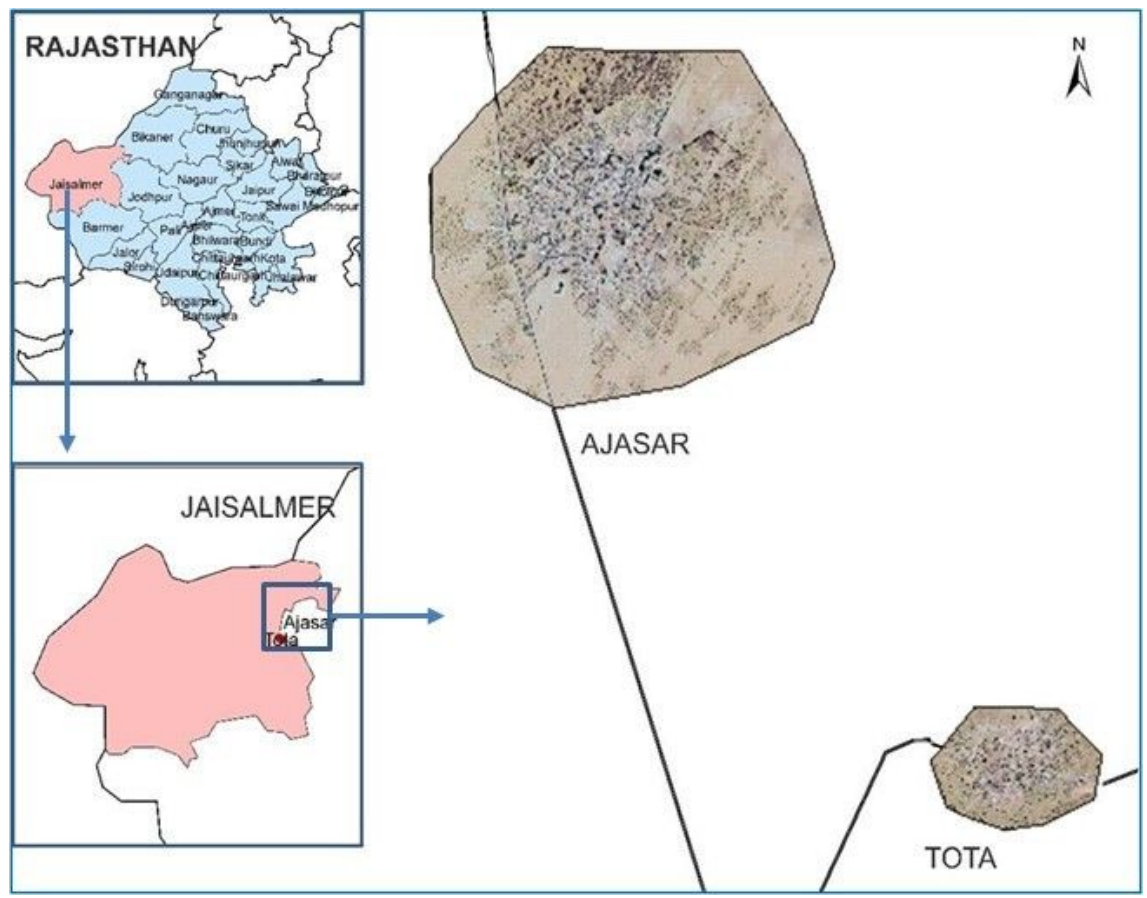

Page 6/9 


\section{Figure 1}

Map showing study areas of Jaisalmer district in Rajasthan, India Note: The designations employed and the presentation of the material on this map do not imply the expression of any opinion whatsoever on the part of Research Square concerning the legal status of any country, territory, city or area or of its authorities, or concerning the delimitation of its frontiers or boundaries. This map has been provided by the authors.

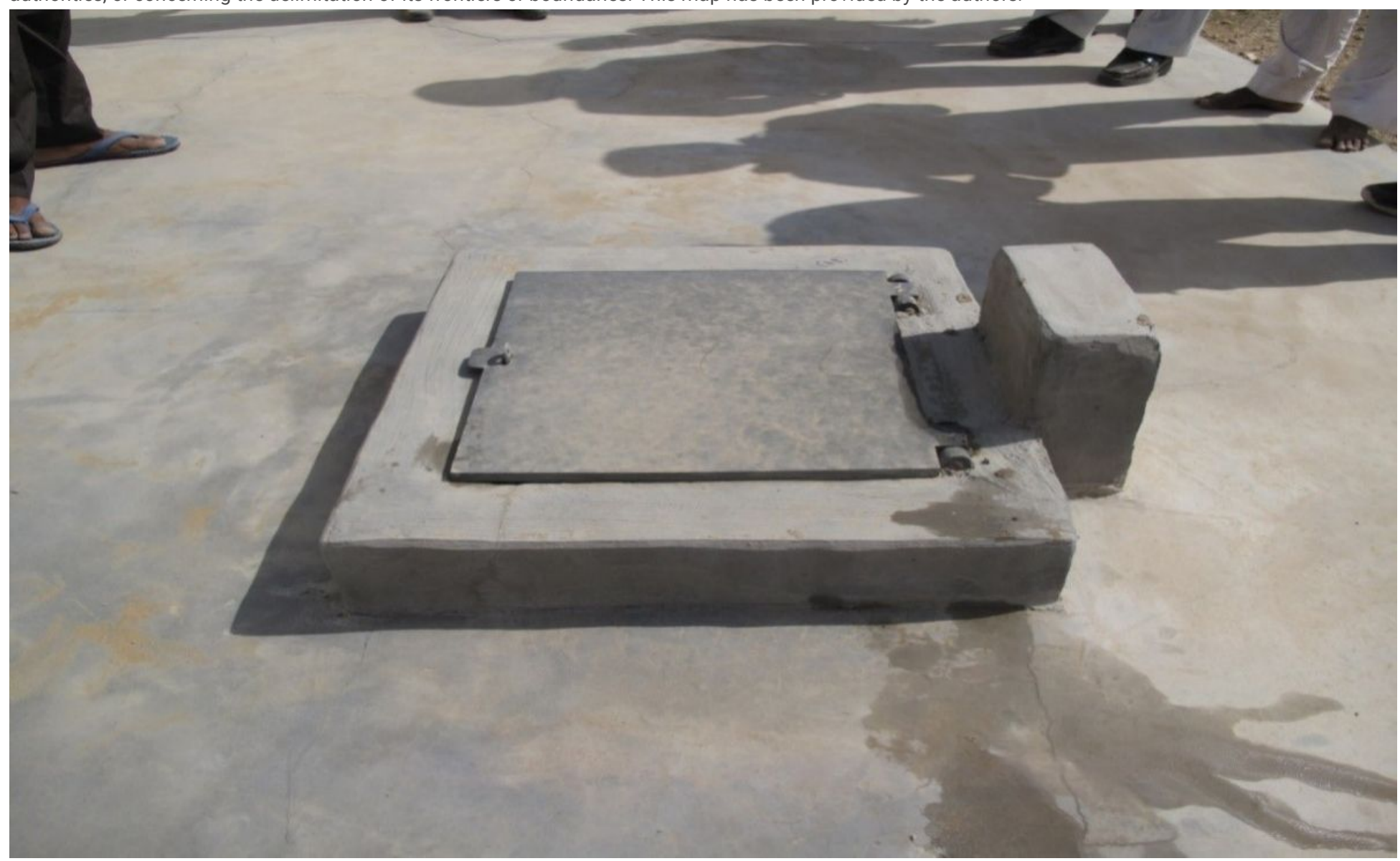

Figure 2

Polyvinyl mosquito proof lid of size $18 \times 18$ inches
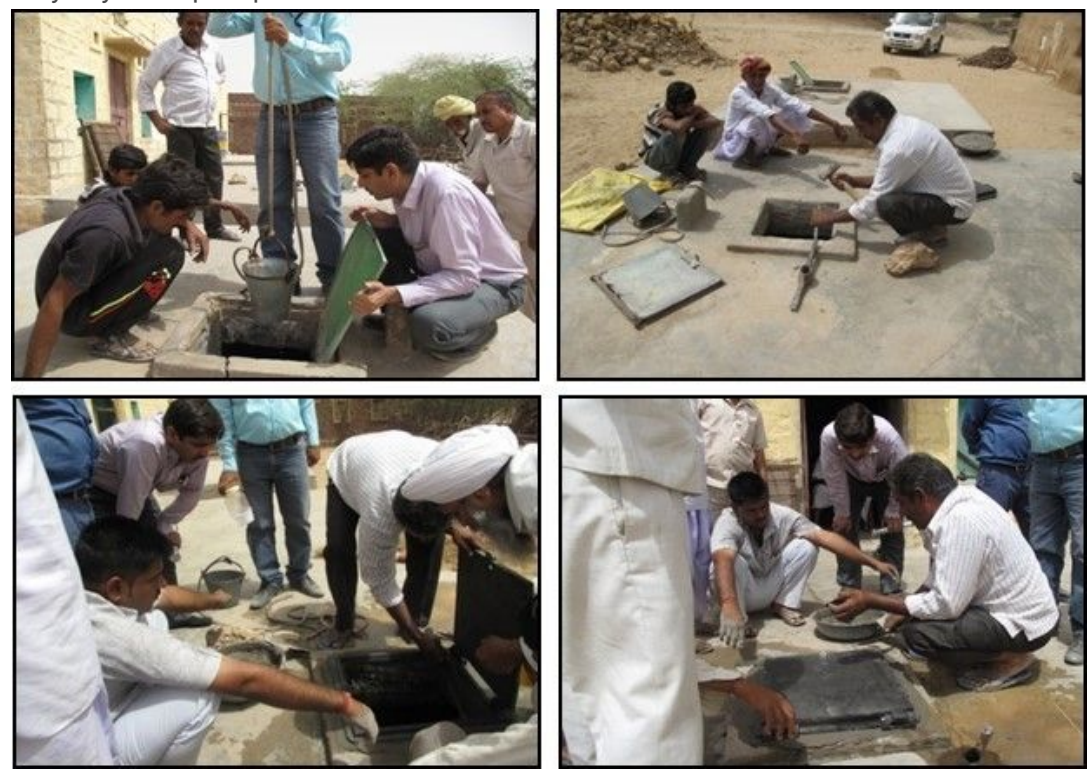

\section{Figure 3}

Training/demonstration of replacement of Tanka's lid 


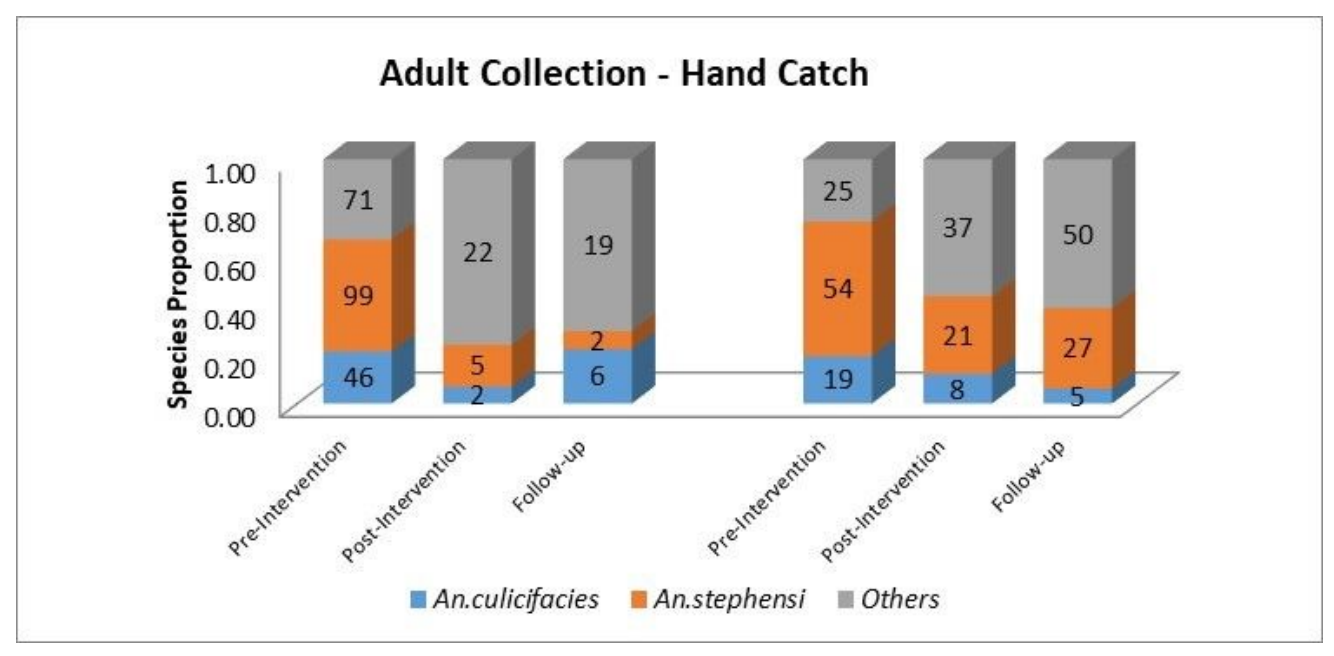

\section{Figure 4}

Proportion of adult species collected by hand-catch method in intervention and non-intervention villages before and after replacement of lids.

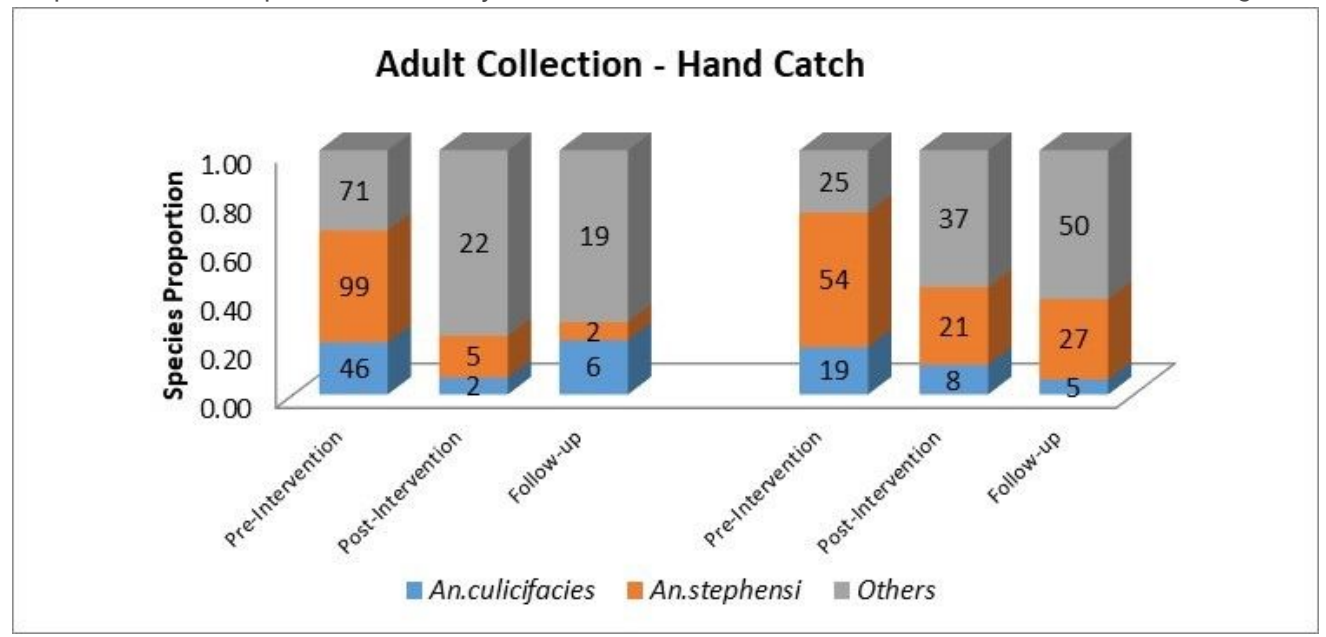

\section{Figure 5}

Proportion of adult species collected by total-catch method in intervention and non-intervention villages before and after replacement of lids

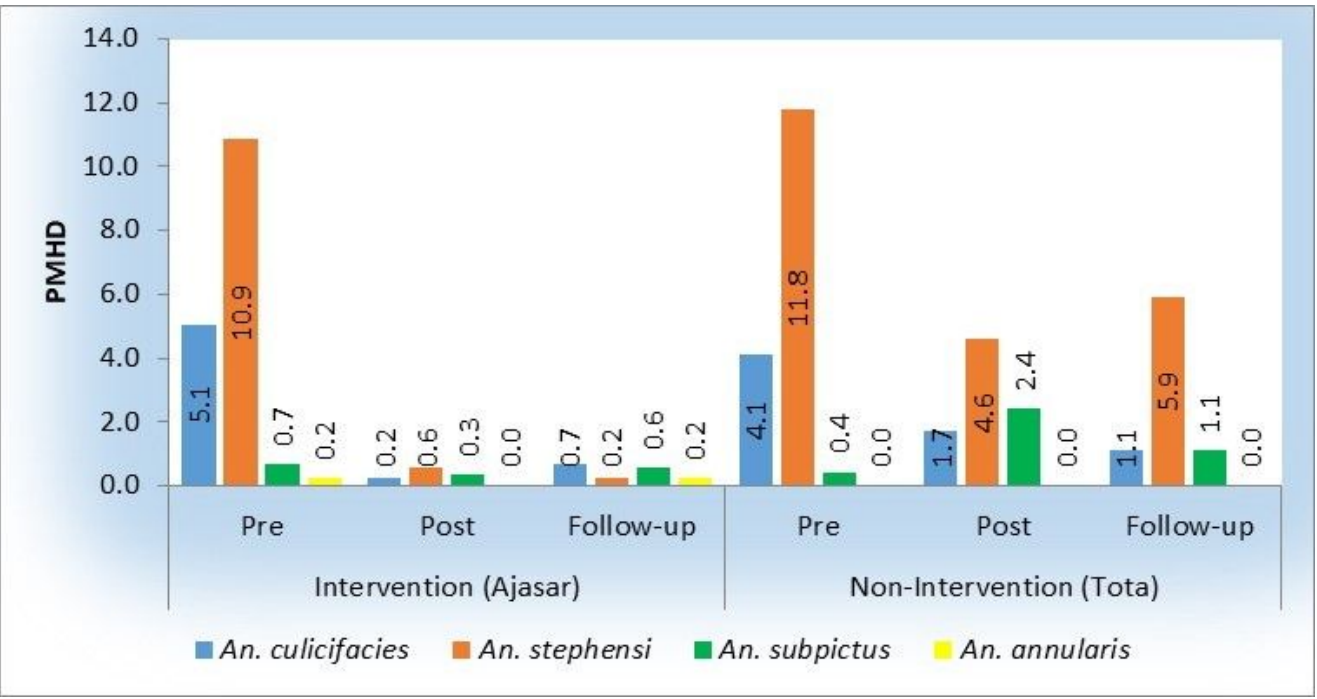

\section{Figure 6}

Per man hour density of Anopheles species in intervention and non-intervention village pre and post lid replacement 


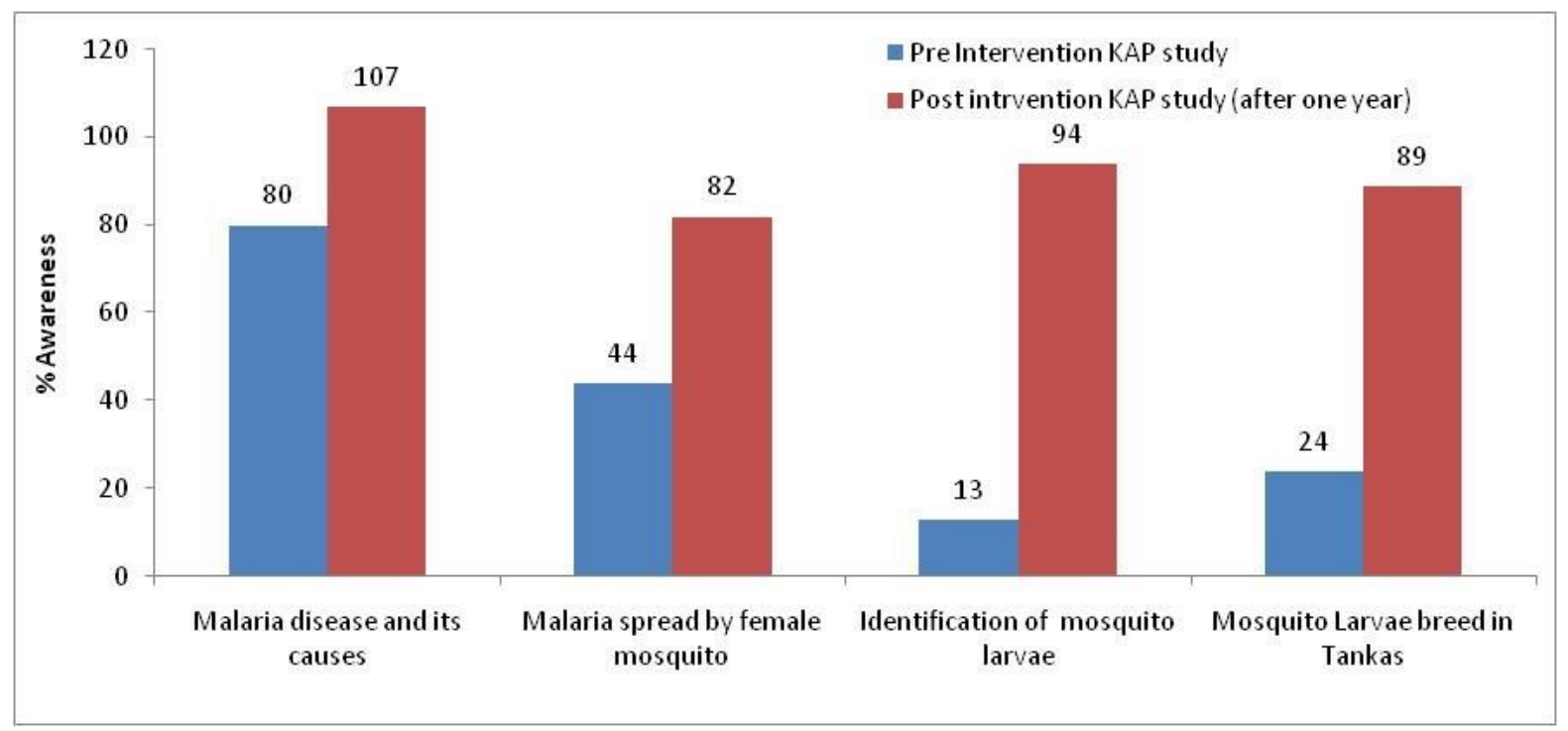

Figure 7

Awareness among the community about malaria and its cause $(n=120)$ 